\title{
Vaccinia virus anti-apoptotic F1L is a novel Bcl-2-like domain-swapped dimer that binds a highly selective subset of BH3-containing death ligands
}

\author{
M Kvansakul ${ }^{1}$, H Yang ${ }^{1}$, WD Fairlie ${ }^{1}$, PE Czabotar ${ }^{1}$, SF Fischer ${ }^{1}$, MA Perugini ${ }^{2}$, DCS Huang ${ }^{1}$ and PM Colman ${ }^{\star, 1}$
}

Apoptosis is an important part of the host's defense mechanism for eliminating invading pathogens. Some viruses express proteins homologous in sequence and function to mammalian pro-survival Bcl-2 proteins. Anti-apoptotic F1L expressed by vaccinia virus is essential for survival of infected cells, but it bears no discernable sequence homology to proteins other than its immediate orthologues in related pox viruses. Here we report that the crystal structure of F1L reveals a Bcl-2-like fold with an unusual $\mathrm{N}$-terminal extension. The protein forms a novel domain-swapped dimer in which the $\alpha 1$ helix is the exchanged domain. Binding studies reveal an atypical BH3-binding profile, with sub-micromolar affinity only for the BH3 peptide of pro-apoptotic Bim and low micromolar affinity for the BH3 peptides of Bak and Bax. This binding interaction is sensitive to F1L mutations within the predicted canonical BH3-binding groove, suggesting parallels between how vaccinia virus F1L and myxoma virus M11L bind $\mathrm{BH} 3$ domains. Structural comparison of $\mathrm{F} 1 \mathrm{~L}$ with other $\mathrm{Bcl}-2$ family members reveals a novel sequence signature that redefines the BH4 domain as a structural motif present in both pro- and anti-apoptotic Bcl-2 members, including viral Bcl-2-like proteins. Cell Death and Differentiation (2008) 15, 1564-1571; doi:10.1038/cdd.2008.83; published online 13 June 2008

In higher organisms, programmed cell death (apoptosis) is a prominent feature of the response to viral infection. The central role of the Bcl-2 protein family in maintaining cell survival or driving apoptosis, thereby removing infected, damaged or unwanted cells, is reflected by the expression of sequence, structural and functional orthologues of $\mathrm{Bcl}-2$ by certain viruses. ${ }^{1}$ The $\mathrm{Bcl}-2$-related proteins share the presence of one or more of four $\mathrm{Bcl}-2$ homology $(\mathrm{BH})$ domains in their primary sequences and act either to promote cell survival or to counter this. ${ }^{2}$ Pro-survival family members such as mammalian $\mathrm{Bcl}-2, \mathrm{Bcl}-\mathrm{x}_{\mathrm{L}}, \mathrm{Bcl}-\mathrm{w}, \mathrm{Mcl}-1$ and $\mathrm{A} 1$ block apoptosis until their protective effect is countered by binding of proapoptotic BH3-only proteins, such as Bim, Bad or Noxa. ${ }^{2,3}$ Pro-survival $\mathrm{Bcl}-2$ proteins contain multiple $\mathrm{BH}$ domains, whereas the distantly related $\mathrm{BH} 3$-only proteins contain only the $\alpha$-helical $\mathrm{BH} 3$ domain, which binds a receptor-like groove on the pro-survival proteins, thereby inactivating them. ${ }^{4,5}$ Upon activation, pro-apoptotic Bax and Bak, which are essential for apoptosis to proceed, ${ }^{6}$ oligomerize to cause organellar damage.

The viral Bcl-2-like proteins, including those expressed by adenovirus, Kaposi sarcoma-associated herpesvirus, Epstein-Barr virus (EBV) and $\gamma$-herpesvirus 68, are all required for successful viral propagation and/or persistence. However, other viruses express anti-apoptotic proteins that are unrelated by sequence to any known cell death regulator. These include the myxoma virus $\mathrm{M} 11 \mathrm{~L},{ }^{7}$ cytomegalovirus $\mathrm{VMIA}^{8}$ and vaccinia virus $\mathrm{F} 1 \mathrm{~L}^{9}$ and E3L. ${ }^{10}$ Despite the lack of sequence similarity, M11L adopts a Bcl-2-like fold. ${ }^{11}$ Moreover, the structure of $\mathrm{M} 11 \mathrm{~L}$ in complex with the $\mathrm{BH} 3$ peptide from Bak revealed that the canonical $\mathrm{BH} 3$-binding groove is utilized in this interaction, and tests of M11L mutants showed that its anti-apoptotic action relies on binding to Bak and/or Bax, less so to $\mathrm{BH} 3-o n l y$ proteins. ${ }^{11}$ The vaccinia virus $\mathrm{N} 1 \mathrm{~L}$ protein also displays a Bcl-2-like fold, ${ }^{12,13}$ even though, like myxoma virus $\mathrm{M} 11 \mathrm{~L}$, its sequence does not resemble that of $\mathrm{Bcl}-2$. Vaccinia virus lacking N1L replicate normally in cell culture, but are attenuated in animal models. ${ }^{14}$ The function of $\mathrm{N} 1 \mathrm{~L}$ is not fully understood, but its three-dimensional fold and ability to bind $\mathrm{BH} 3$ peptides suggest a role in modulating apoptosis. ${ }^{12,13}$

Vaccinia virus F1L inhibits the mitochondrial pathway of apoptosis and, when overexpressed in mammalian cells, it localizes via its C-terminal tail to the mitochondria. ${ }^{9} \mathrm{~F} 1 \mathrm{~L}$ interacts with the isolated $\mathrm{BH} 3$ domain of $\mathrm{Bim}$ and an F1L-deficient virus potently causes Bak/Bax-mediated apoptosis. ${ }^{10}$ Unlike the parent, this mutant virus fails to block Bak activation triggered by staurosporine. In the absence of any apoptotic stimuli, F1L reportedly binds to endogenous Bak but not to pro-survival Bcl-2 family members. ${ }^{9,15} \mathrm{~F} 1 \mathrm{~L}$ also inhibits the activation of $\mathrm{Bax}$ and its translocation to mitochondria following an apoptotic stimulus, possibly because it interacts with Bim. ${ }^{16}$

To elucidate at a molecular level how F1L counters apoptosis, we solved by X-ray crystallography the threedimensional structure of $F 1 L$ isolated from the modified vaccinia virus Ankara strain (MVA). Unexpectedly, F1L

\footnotetext{
${ }^{1}$ The Walter and Eliza Hall Institute of Medical Research, 1G Poyal Parade, Parkville, Victoria 3050, Australia and ${ }^{2}$ Department of Biochemistry and Molecular Biology, The University of Melbourne, Parkville, Victoria 3010, Australia

${ }^{*}$ Corresponding author: PM Colman, The Walter and Eliza Hall Institute of Medical Research, 1G Poyal Parade, Parkville, Victoria 3050, Australia.

Tel: + 6139345 2634; Fax: + 6139345 2686; E-mail: pcolman@ wehi.edu.au

Keywords: apoptosis; $\mathrm{Bcl}-2$; $\mathrm{BH} 4$ domain; vaccinia virus

Abbreviations: BH, Bcl-2 homology; EBV, Epstein-Barr virus; ITC, isothermal calorimetry; KD, dissociation constant; MVA, modified vaccinia virus Ankara; VV, vaccinia virus; WT, wild-type

Received 05.2.08; revised 21.4.08; accepted 16.5.08; Edited by JM Hardwick; published online 13.6.08
} 
adopts a Bcl-2-like fold by the formation of an unusual domainswapped dimer. Our structure provides a rationale for how $\mathrm{BH} 3$ domains interact with F1L. Previously, a small region of F1L (residues 64-84) was reported to directly interact with Bak, potentially constituting a 'BH3-like' domain in F1L. ${ }^{17}$ This conclusion is incompatible with the structure of $\mathrm{F} 1 \mathrm{~L}$ we report here.

\section{Results}

F1L adopts a domain-swapped Bcl-2-like fold. The crystal structure of F1L reveals that the polypeptide folds into eight helical segments, here labelled $\alpha 0-\alpha 7$ (Figures 1a and 2). The $\alpha 1$ helix is swapped ${ }^{18}$ into a neighbouring polypeptide that is related by a crystallographic two-fold symmetry axis (Figure $1 \mathrm{~b}$ ). The resulting arrangement of $\alpha 1^{*}$, $\alpha 2-\alpha 7$ forms the helical bundle characteristic of Bcl-2 family proteins, ${ }^{19} \alpha 1^{*}$ denoting the helix from the partner polypeptide in the dimer. Bcl- $x_{L}$ (PDB code 1MAZ) is the closest structural match found by the DALI server and yet it has only $12 \%$ sequence identity with F1L over the 129 residues of $\mathrm{F} 1 \mathrm{~L}$ 's $\mathrm{Bcl}-2$-like region. The loop region between $\alpha 1$ and $\alpha 2$ of $F 1 L$ is unusually short ( 2 amino acids) when compared to other monomeric Bcl-2 family members such as $\mathrm{Bcl}-\mathrm{x}_{\mathrm{L}}$, where the homologous loop contains $\sim 60$ amino acids (Figure 2), suggesting a rationale for the $\alpha 1$ domain swap (see below). Pro-survival $\mathrm{Bcl}-2$ family proteins engage $\mathrm{BH} 3$ ligands via a hydrophobic groove largely comprising helices $\alpha 2-\alpha 5$. In the F1L structure, hydrophobic amino acids from helices $\alpha 2, \alpha 4$ and $\alpha 5$ form such a groove, together with the largely disordered ' $\alpha 3$ ' segment, so labelled only for consistency with the $\mathrm{Bcl}-2$ family protein structure.

The $\mathrm{N}$-terminal extension, $\alpha 0$, is novel in known $\mathrm{Bcl}-2$ structures. It is folded against the $\alpha 5 / \alpha 6$ corner of its own polypeptide. The $\mathrm{N}$-terminal end of $\alpha 0$ partially fills the $\mathrm{BH} 3-$ binding groove of a neighbouring molecule, forming a network of crystal contacts. No evidence of higher-order oligomers of $\mathrm{F} 1 \mathrm{~L}$ in solution can be detected (see below), suggesting that this interaction is a crystallographic artefact. A 27-mer peptide corresponding to $\alpha 0$ shows no binding to $\mathrm{F} 1 \mathrm{~L}$ in solution using ITC (data not shown).

The F1L dimer. As in monomeric Bcl-2 family proteins, the $\alpha 1$ helix engages on one side in intimate contacts with the core of the helix-bundle fold. Specifically, F1L residues V62, A65, V66, Y69 and M70 from helix $\alpha 1^{*}$ engage in canonical interactions with the core of the Bcl-2-like helix bundle (Y89, I182, V179, F178, I146 and C174). However, in mammalian pro-survival proteins, the other side of helix $\alpha 1$ is partially solvent-shielded by the loop connecting to helix $\alpha 2$, whereas
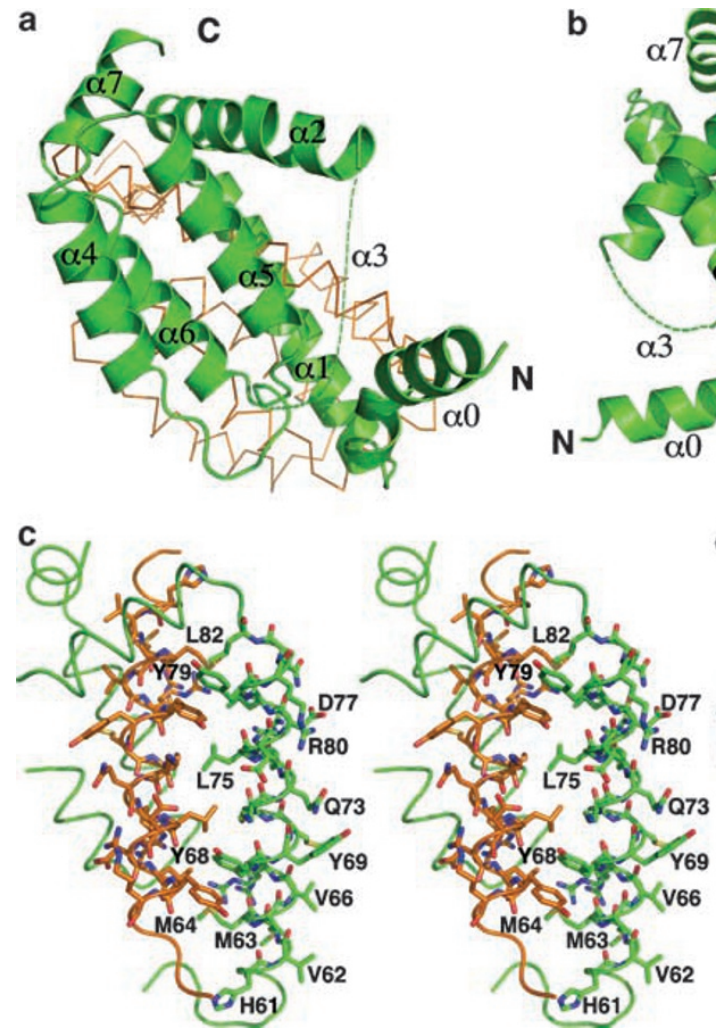

d

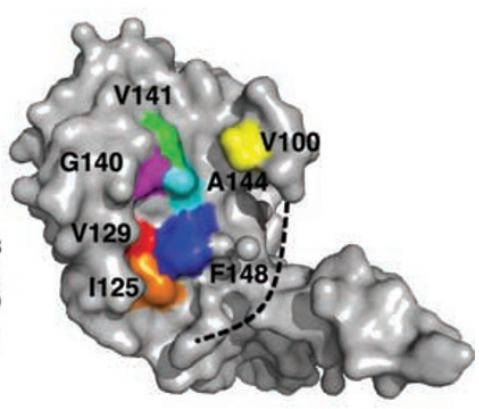

Figure 1 (a) Structure of F1L. One monomer is shown as a cartoon (green), with helices $0-7$ labelled, and the dotted line indicating the position of the disordered ' $\alpha 3$ ' segment. This view looks into the putative BH3-binding grove, which is formed by segments $\alpha 2-\alpha 5$. The second monomer is shown as a trace (orange). (b) Structure of the F1L homodimer. Monomeric F1L subunits are shown as a cartoon in green and orange. The view is down the two-fold symmetry axis between the domain-swapped $\alpha 1$ helices. (c) Stereo-view of the F1L dimer interface. The view is preserved from (b). For clarity, only $\alpha 1$ is shown for the orange monomer. Important residues in the interface are labelled and shown for the green monomer. (d) Molecular surface representation of F1L. The view is preserved from (a). F1L residues mutated in the binding assays (Figure $3 b$ ) are highlighted in colour. Location of the disordered ' $\alpha 3$ ' segment is indicated by a dotted line 


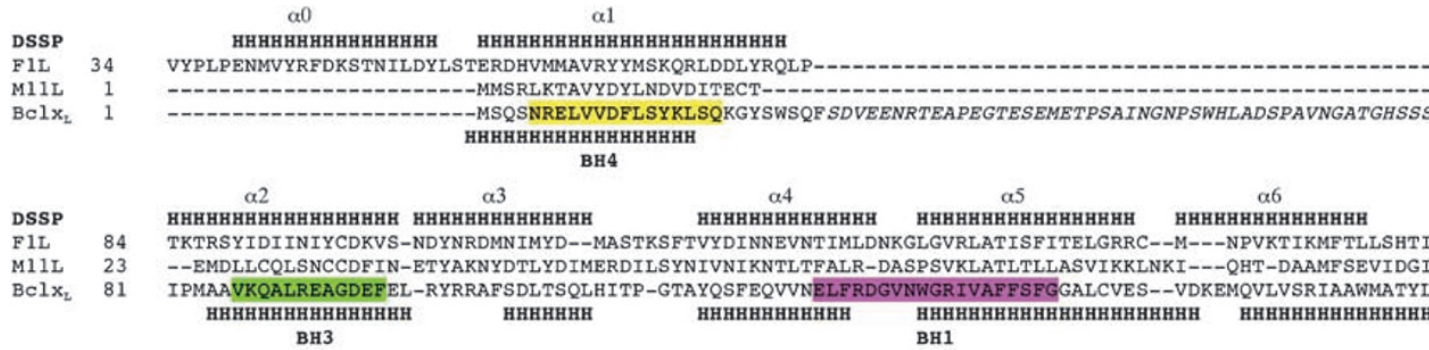
BH1

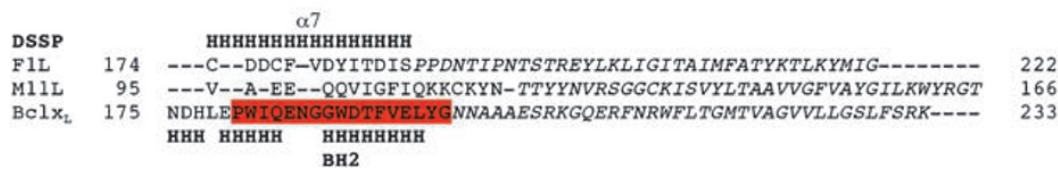

Figure 2 Sequence and structural alignment of $\mathrm{F} 1 \mathrm{~L}$ with $\mathrm{M} 11 \mathrm{~L}^{11}$ and $\mathrm{Bcl}-\mathrm{x}_{\mathrm{L}} \cdot{ }^{19}$ Coloured boxes denote the $\mathrm{BH} 1-4$ domains in $\mathrm{Bcl}-\mathrm{x}_{\mathrm{L}}$. Helices in $\mathrm{F} 1 \mathrm{~L}$ and $\mathrm{Bcl}-\mathrm{x}_{\mathrm{L}}$ are $\mathrm{marked}$ ' $\mathrm{H}$ ', and residues in italics were not included when generating the alignment

in F1L it forms the dimer interface through hydrophobic residues that include $\mathrm{M} 64, \mathrm{Y} 68, \mathrm{~L} 75, \mathrm{Y} 79$ and $\mathrm{L} 82$ (Figure 1c). The putative BH3-binding grooves lie on opposite sides of the resulting dimer. Furthermore, in the dimer, the $\alpha 7$ C-terminal helices are approximately parallel, potentially allowing the C-terminal transmembrane segments to anchor the dimer into mitochondrial membranes without occluding either of the BH3-binding sites on the F1L dimmer.

$\mathrm{F} 1 \mathrm{~L}$ is a dimer in solution. During recombinant protein purification, F1L eluted at a volume commensurate with a dimeric form (data not shown). Sedimentation velocity studies by analytical ultracentrifugation at an initial protein concentration of $1.0 \mathrm{mg} / \mathrm{ml}$ revealed a single species with an apparent molar mass of $43 \mathrm{kDa}$ and sedimentation coefficient $\left(s_{20, w}\right)$ of 3.4 S (Table 1; data not shown). These results support the conclusion that the novel dimeric structure observed in the crystals is not an artefact of crystallization, rather it is a property of the protein in dilute solution. To confirm the role of the length of the $\alpha 1 / \alpha 2$ loop in dimer formation, we characterized three different $\mathrm{Bcl}-\mathrm{x}_{\mathrm{L}}$ constructs that lack their C-terminal membrane anchor $\left(\mathrm{Bcl}-\mathrm{x}_{\mathrm{L}} \Delta \mathrm{C}\right)$ by gel filtration, clearly showing that $\mathrm{BCl}-\mathrm{x}_{\mathrm{L}} \Delta \mathrm{C}$ consisting of the full cytoplasmic domain and the construct lacking amino acids 45-84 are monomeric in solution, but removal of amino acids 27-82 generates a dimeric form (Figure 4). We confirmed the dimeric state of Bcl- $x_{L} \Delta \mathrm{C}$ lacking amino acids 27-82 using analytical ultracentrifugation, which revealed a single species with an apparent molar mass of $33 \mathrm{kDa}$ and sedimentation coefficient $\left(s_{20, w}\right)$ of $3.0 \mathrm{~S}$ (Table 1; data not shown). Various attempts to engineer a monomeric form of F1L were unsuccessful (see Supplementary results).

Bcl-2 homology domains. F1L adopts a Bcl-2-like fold, even though at a primary sequence level no homology is detectable to any other member of the Bcl-2 family of proteins. Considering the absence of signature $\mathrm{BH}$ domains in $\mathrm{F} 1 \mathrm{~L}$, we examined the structural segments in $\mathrm{F} 1 \mathrm{~L}$ that correspond to the $\mathrm{BH}$ domains in other $\mathrm{Bcl}-2$ members. The $\mathrm{BH} 4$ domain comprises much of the $\mathrm{N}$-terminal helix $(\alpha 1)$ of the eight-helix fold of Bcl-2. Helix $\alpha 1$ packs against elements of $\alpha 2(\mathrm{BH} 3), \alpha 5(\mathrm{BH} 1)$ and $\alpha 8(\mathrm{BH} 2)$, but on the opposite side of the protein to the binding site for exogenous $\mathrm{BH} 3$ ligands.
Table 1 Analytical ultracentrifugation of $\mathrm{F} 1 \mathrm{~L}$ and $\mathrm{Bcl}-\mathrm{x}_{\mathrm{L}}$

\begin{tabular}{lccccc}
\hline Sample & $\boldsymbol{s}_{20, w^{\mathbf{0}}}{ }^{\mathbf{a}}(\mathbf{S})$ & $\boldsymbol{M}_{\mathbf{r}}{ }^{\mathbf{b}}$ & $\boldsymbol{M}^{\mathbf{c}}(\mathbf{k D a})$ & $\boldsymbol{f} / \boldsymbol{f}_{\mathbf{0}}{ }^{\mathbf{d}}$ & $\boldsymbol{a} / \mathbf{b}^{\mathbf{e}}$ \\
\hline $\mathrm{F} 1 \mathrm{~L}$ & 3.4 & 21429 & 42.7 & 1.35 & 3.7 \\
$\mathrm{BCl}-\mathrm{X}_{\mathrm{L}} \mathrm{NL}$ & 3 & 17901 & 33 & 1.31 & 3.4
\end{tabular}

${ }^{\text {a }}$ Standardized sedimentation coefficient taken from the ordinate maximum of the $c(s)$ distribution (data not shown). ${ }^{b}$ Relative monomeric molecular mass $\left(M_{\mathrm{r}}\right)$ determined from the amino-acid sequence. ${ }^{c}$ Apparent molar mass $(M)$ taken from the ordinate maximum of the $c(M)$ distribution. ${ }^{\mathrm{d}}$ Frictional coefficient of the dimer calculated using the $v$-bar method. ${ }^{38}$ e Axial ratio $(a / b)$ assuming a prolate ellipsoidal structure calculated using the v-bar method. ${ }^{38}$

The structural superposition shows a conserved sequence motif in $\alpha 1$ (Figure 5), comprising $\phi_{1} \phi_{2} X X \phi_{3} \phi_{4}$, where $X$ is any amino acid, $\phi$ is a hydrophobic residue, $\phi_{1} \phi_{2}$ and $\phi_{4}$ are aliphatic amino acids and $\phi_{3}$ is an aromatic amino acid (Figure 5).

Ligand binding of F1L. BH3-only proteins have been shown to initiate apoptotic signalling in response to a variety of signals, leading to oligomerization of proapoptotic Bax and Bak. To gain further insight into the biological role of $\mathrm{F} 1 \mathrm{~L}$, we assessed the binding of different $\mathrm{BH} 3$ domain peptides from mammalian $\mathrm{BH} 3-$ only proteins, from the pro-apoptotic proteins Bak and Bax, and from Beclin-1 and Mule (Figure 3a). The results from isothermal calorimetry (Supplementary Figure S1) and from competition and direct binding studies (Figure 3 ) in a Biacore biosensor are in good agreement. Only a 26-mer peptide spanning Bim $\mathrm{BH} 3$ binds tighter than $1 \mu \mathrm{M}$ to $\mathrm{F} 1 \mathrm{~L}$, the $K_{\mathrm{d}}$ being $250 \mathrm{nM}$ (Figure $3 \mathrm{a}$ and Supplementary Figure S1). Unexpectedly, F1L does not measurably interact with a 26-mer Bak $\mathrm{BH} 3$ peptide, as revealed by the Biacore (S51) direct binding assay, whereas a 28-mer Bax $\mathrm{BH} 3$ binds weakly with a $K_{\mathrm{d}}$ of $\sim 2 \mu \mathrm{M}$. However, using isothermal calorimetry, we were able to measure binding of a 26-mer Bak BH3 peptide with a $K_{\mathrm{d}}$ of 4.3 $\mu \mathrm{M}$ (Supplementary Figure S1). Failure to express F1L in mammalian cells frustrated our attempts to corroborate these interactions in vivo.

Mutagenesis studies. To further characterize the interaction between $\mathrm{F} 1 \mathrm{~L}$ and $\mathrm{BH} 3$ domain peptides, we 
a

WT F1L binding to $\mathrm{BH}$ ligands

\begin{tabular}{lc} 
Ligand & $\boldsymbol{K}_{\mathbf{D}}(\mathbf{n M})$ \\
\hline hsBad & $>1000$ \\
hsBid & $>1000$ \\
hsBim & $250 \pm 142$ \\
mmBmf & $>1000$ \\
mmHrk & $>1000$ \\
hsNoxa & $>1000$ \\
hsPuma & $>1000$ \\
mmMule & $>1000$ \\
mmBeclin & $>1000$ \\
& \\
hsBak & $>1000$ \\
hsBax 28-mer & $1850 \pm 150$
\end{tabular}

C

WT F1L binding to Bim mutants

\begin{tabular}{lr} 
Peptide & IC $_{\mathbf{5 0}}$ ( $\mathbf{n M}$ ) \\
\hline I58A & $>10000$ \\
A59E & $4000 \pm 1000$ \\
L62A & $>10000$ \\
I65A & $>10000$ \\
G66E & $>10000$ \\
D67A & $290 \pm 32$ \\
F69A & $3185 \pm 815$ \\
WT & $230 \pm 37$
\end{tabular}

Figure 3 Binding data for $\mathrm{F} 1 \mathrm{~L}$ and its ligands. (a) BH3-binding profile of wildtype (WT) F1L. $K_{d}$ values were determined by Biacore S51 assays. (b) Mutagenesis mapping of $\mathrm{F} 1 \mathrm{~L}$ binding groove. $\mathrm{IC}_{50}$ values shown were measured for mutant $\mathrm{F} 1 \mathrm{~L}$ binding to WT Bim BH3. (c) Binding of mutant Bim BH3 peptides to WT F1L. (d) Binding of mutant Bim BH3 peptides to $\mathrm{F} 1 \mathrm{~L} I 125 \mathrm{~F}$. IC $\mathrm{C}_{50}$ values for $(\mathbf{b}-\mathbf{d})$ were determined by competition experiments using the Biacore 3000 system; NB indicates that no binding was detected

performed site-directed mutagenesis on $\mathrm{F} 1 \mathrm{~L}$ and determined the effect of these mutations on Bim binding (Figures 1d and 3b). Mutants V100A, I125A, G140F, F148A and F148E completely abrogated binding. The V100F, V129L and V141L mutations did not significantly impair Bim binding, whereas I125F, V141F and A144F increased F1L affinity for Bim.

We then investigated the effect of mutations in Bim on binding to wild-type F1L (Figure 3c). Substitution of each of the four conserved hydrophobic residues of the $\mathrm{Bim} \mathrm{BH} 3$ domain with alanine (I58A, L62A, I65A and F69A) compromises binding, as does substitution of the two small amino acids (A59 and G66) with glutamic acid, whereas substitution of aspartic acid (D67) with alanine is tolerated. The F1L mutant I125F, which binds more tightly than wild-type F1L to wild-type $\mathrm{Bim} \mathrm{BH} 3$, is also sensitive to mutation of the signature $\mathrm{BH} 3$ amino acids of Bim (Figure $3 \mathrm{~d}$ ). These results support a similar model for $\mathrm{Bim} \mathrm{BH} 3$ binding to $\mathrm{F} 1 \mathrm{~L}$ as it does to $\mathrm{BCl}-\mathrm{x}_{\mathrm{L}}{ }^{5}$ or $\mathrm{Mcl}-1,{ }^{20}$ but a three-dimensional structure of an $\mathrm{F} 1 \mathrm{~L}: \mathrm{BH} 3$ domain complex is needed to confirm the results.

\section{Discussion}

Oligomerization of Bcl-2 family members is intimately associated with apoptosis signalling. To date, structural studies of such oligomers have addressed only the heterodimerization of pro-survival Bcl-2 family members with isolated $\mathrm{BH} 3$ domains, but homo-oligomers of Bak and Bax are widely believed to presage apoptosis. ${ }^{3}$ This report of the structure of

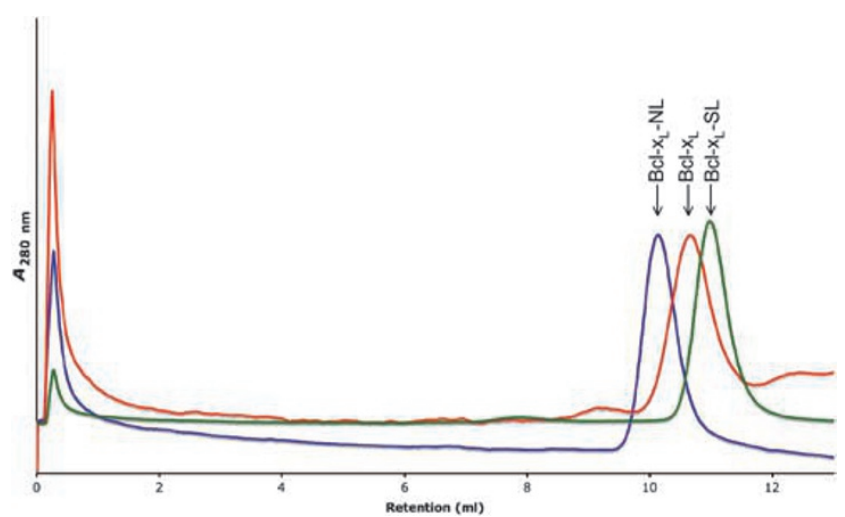

Figure 4 Loop-deleted $B c l-x_{L}$ runs as a dimer on gel filtration. Purified $B c l-x_{L}$ (predicted $\mathrm{MW}=23778), \mathrm{Bcl}-\mathrm{x}_{\mathrm{L}}$ with a shortened $\alpha 1-\alpha 2$ loop $\left(\mathrm{Bcl}-\mathrm{x}_{\mathrm{L}}-\mathrm{SL}, \Delta \mathrm{aa}\right.$ 45-84, predicted $M W=20780)$ and $B c l-x_{L}$ with no $\alpha 1-\alpha 2$ loop $\left(B c l-x_{L}-N L, \Delta a a\right.$ 27-82, predicted $M W=17901$ ) were passed over a Sup75 10-300 column equilibrated with $20 \mathrm{mM}$ Tris $\mathrm{pH} 8.0$ and $150 \mathrm{mM} \mathrm{NaCl}$. All proteins lacked the Cterminal transmembrane anchor $(\triangle \mathrm{C} 25)$. $\mathrm{Bcl}-\mathrm{x}_{\mathrm{L}} \mathrm{S} \mathrm{SL}$ also contained a $\mathrm{C}$-terminal His tag. $\mathrm{Bcl}-\mathrm{x}_{\mathrm{L}}, \mathrm{Bcl}-\mathrm{x}_{\mathrm{L}}-\mathrm{SL}$ and $\mathrm{Bcl}-\mathrm{x}_{\mathrm{L}}-\mathrm{NL}$ were expressed and purified as described previously ${ }^{4,21,39}$

$\mathrm{F} 1 \mathrm{~L}$ is a novel example of a naturally occurring homodimer of a Bcl-2 family protein. Two examples of domain-swapped homodimers of $\mathrm{Bcl}-2$-like proteins have previously been reported, both for $\mathrm{BCl}-\mathrm{x}_{\mathrm{L}}{ }^{21,22}$ In one case, a dimer was induced by exposure to alkali, resulting in domain swapping of helices $\alpha 6-\alpha 8$. $^{22}$ The crystallization of $\mathrm{Bcl}-\mathrm{x}_{\mathrm{L}}$ with the Beclin $\mathrm{BH} 3$ domain ${ }^{21}$ displays an $\alpha 1$ domain-swapped dimer, similar but not identical to that reported here for F1L. The dimer in that case was attributed to a crystallization artefact. However, analytical ultracentrifugation and gel-filtration analysis of $\mathrm{Bcl}-\mathrm{X}_{\mathrm{L}}$ with an identically shortened loop indicate that the protein is a dimer in solution (Figure 4 and Table 1). Thus, $\alpha 1 / \alpha 2$ loop length can control dimerization of Bcl-2-like proteins. In the F1L structure, $\alpha 1$ is extended (Figure 2) and the connecting loop to $\alpha 2$ is short, both conditions that promote homodimerization by domain swapping. Dimerization driven by swapping of the $\alpha 1$ domains may be of special interest because of the body of data that suggest exposure of the $N$ terminus of Bax and Bak as a signature of their activation. ${ }^{23,24} \mathrm{~N} 1 \mathrm{~L}$ also exists as a dimer, ${ }^{14}$ but no domain swapping occurs in that case. ${ }^{12,13}$

Other structural studies of $\mathrm{Bcl}-2$ family proteins suggest that the fold is largely unaffected by the presence or absence of the C-terminal membrane anchor. If the C-terminal segments, absent in our construct, are taken into consideration, the dimer structure we describe is compatible with membrane anchoring (see, for example, Figure $1 \mathrm{~b}$, and note the dyadrelated $\alpha 7$ segments projecting towards the viewer). Furthermore, the dimer structure is compatible with Bim $\mathrm{BH} 3$ binding. Bim, like most other BH3-only proteins, is intrinsically unstructured before engagement with a $\mathrm{Bcl}-2$ pro-survival family member. ${ }^{25}$ The $\mathrm{BH} 3$ domain of Bim is located near its C-terminal membrane anchor, ${ }^{26}$ allowing for Bim insertion, in the correct orientation, into the $\mathrm{BH}$-binding groove of the membrane-anchored $\mathrm{F} 1 \mathrm{~L}$ dimer. A similar argument for the binding of full-length Bak to $\mathrm{F} \mathrm{L}^{15}$ is less directly advanced because the Bak $\mathrm{BH} 3$ is not exposed in the structure of C-terminally truncated $\mathrm{Bak}^{27}$ necessitating some 
conformational change to allow its engagement with $\mathrm{F} 1 \mathrm{~L}$, or for that matter with either $\mathrm{Bcl}-\mathrm{x}_{\mathrm{L}}$ or $\mathrm{Mcl}-1 .{ }^{28}$

Postigo et al. ${ }^{17}$ observed that the first 56 amino acids (in MVA strain) (that is, up to and including the first two residues of $\alpha 1$ ) of $F 1 L$ are not required for suppression of apoptosis. Whether or not they have another function is unclear. Therefore, truncation of the $\mathrm{N}$-terminal residues as described here to obtain soluble expressed protein has no known consequences for apoptosis. Orthologues of F1L in other poxviruses show most variability at the $\mathrm{N}$ terminus, but display 95\% sequence identity over the C-terminal 220 amino acids. ${ }^{29}$ Our alignment of MVA F1L with 12 other orthologues indicates that from MVA F1L residue 16 onwards, the remainder of the sequence is highly conserved within all aligned orthologues (data not shown). The ordered part of our structure commences at residue 34 , and thus represents most of the highly conserved region of $\mathrm{F} 1 \mathrm{~L}$. Removal of amino acids 61-76 (57-72 in MVA strain) results in loss of apoptosissuppressing function. ${ }^{17}$ These residues comprise most of the $\alpha 1$ helix of F1L, and are essential for the integrity of the structure of the dimer and (probably) of the folded protein. Other mutants of the Western Reserve strain described in that study include M67P and the double mutant V66E/V70E, neither mutant preventing UV-induced cell death. In the MVA strain, the homologous residues are M63, V62 and V66. These residues comprise part of the hydrophobic interface between $\alpha 1^{*}$ and the partner domain into which it is swapped (see Figure 1c), and these mutants may well be structurally disruptive.

The absence of a canonical $\mathrm{BH} 3$ domain sequence in $\mathrm{F} 1 \mathrm{~L}$ suggests that its interaction with Bak is more likely to involve the $\mathrm{Bak} \mathrm{BH} 3$ into the $\mathrm{F} 1 \mathrm{~L}$ groove rather than the converse. $\mathrm{F} 1 \mathrm{~L}$ is able to bind $\mathrm{BH} 3$ domains of Bim and (more weakly) Bax, and we propose that this interaction is mediated by the putative $\mathrm{BH} 3-$ binding groove of $\mathrm{F} 1 \mathrm{~L}$ described above. In mammalian $\mathrm{Bcl}-2$ family members, this groove is formed by structural elements that correspond to the $\mathrm{BH} 1, \mathrm{BH} 2$ and $\mathrm{BH} 3$ homology domain sequences, yet no such sequence signatures are evident in F1L. A similar conundrum confronted the explanation for $\mathrm{BH} 3$ binding to $\mathrm{M} 11 \mathrm{~L}$, but was resolved by a crystal structure of $\mathrm{M} 11 \mathrm{~L}$ bound to the Bak $\mathrm{BH} 3$ domain, supported by mutagenesis and functional analysis. ${ }^{11}$ Our mutagenesis studies of the $\mathrm{Bim} \mathrm{BH} 3$ peptide and $\mathrm{F} 1 \mathrm{~L}$, and the associated binding data, support a model in which $\mathrm{F} 1 \mathrm{~L}$ acts as a receptor for the $\mathrm{BH} 3$ domain of the $\mathrm{BH} 3$-only protein $\mathrm{Bim}$. The inconsequential effect of the D67A mutation in Bim on this interaction suggests that D67 in Bim may be adjacent to V141 of $\mathrm{F} 1 \mathrm{~L}$ in the complex. In F1L, V141 is the structural homologue of a conserved arginine in the $\mathrm{BH} 1$ domain of mammalian pro-survival proteins (Figure 2). This result is reminiscent of the lack of any effect on binding to myxoma virus $\mathrm{M} 11 \mathrm{~L}$ when the equivalent $\mathrm{D} 63$ residue was mutated. ${ }^{11}$ $\mathrm{M} 11 \mathrm{~L}$ also lacks the conserved arginine residue in the $\mathrm{BH} 1$ domain. $\mathrm{M} 11 \mathrm{~L}$ and $\mathrm{F} 1 \mathrm{~L}$ are the dominant apoptosis-suppressing proteins in myxoma and vaccinia virus, respectively; they share the Bcl-2-like fold but are themselves only $14 \%$ identical in sequence over the $\mathrm{Bcl}-2$-like region of $\mathrm{F} 1 \mathrm{~L}$.

The apparent absence of any $\mathrm{BH}$ domain in $\mathrm{F} 1 \mathrm{~L}$ prompted us to examine the structural segments in $\mathrm{F} 1 \mathrm{~L}$ that correspond to $\mathrm{BH}$ domains in other $\mathrm{Bcl}-2$ members. This examination

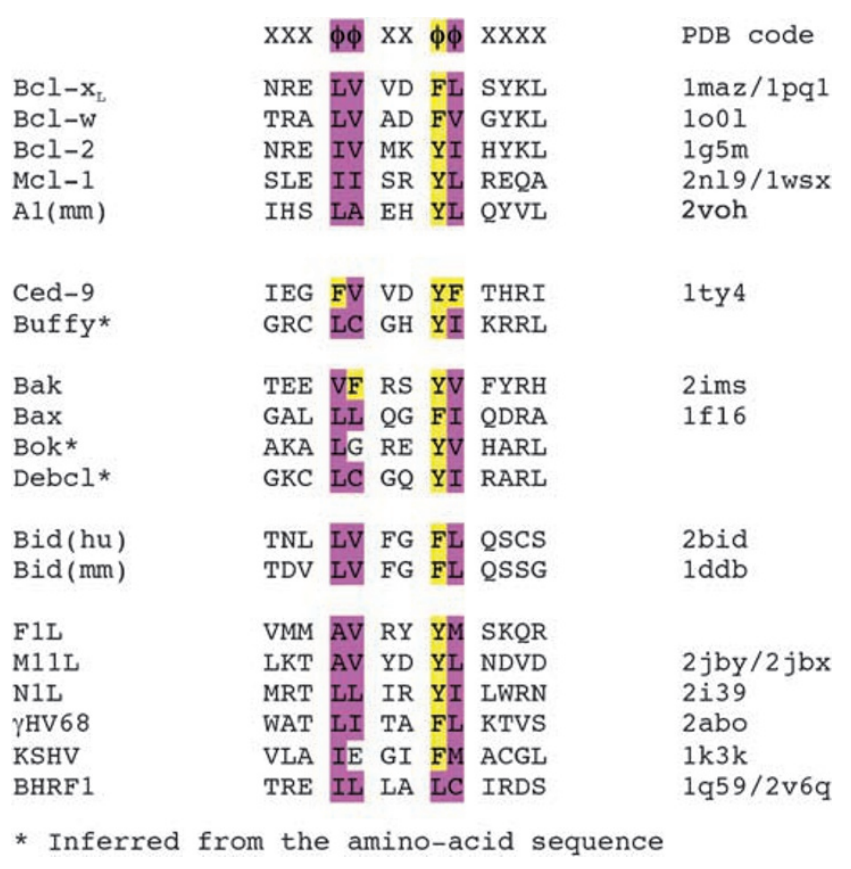

Figure 5 Novel consensus sequence motif redefining the $\mathrm{BH} 4$ domain. The novel BH4 motif is formed by $\phi_{1} \phi_{2} X X \phi_{3} \phi_{4}$, where $\mathrm{X}$ is any amino acid, $\phi$ is a hydrophobic residue and $\phi_{3}$ is an aromatic residue. PDB accession codes ${ }^{40}$ are given in parentheses for each structure

uncovered a conserved sequence motif $-\phi_{1} \phi_{2} X X \phi_{3} \phi_{4}-$ for the $\mathrm{BH} 4$ domain, where $\mathrm{X}$ is any amino acid, $\phi_{1} \phi_{2}$ and $\phi_{4}$ are aliphatic residues and $\phi_{3}$ is an aromatic residue (Figure 5). Some reports claim that pro-apoptotic Bax and Bak have no $\mathrm{BH} 4$ domain and the presence or absence of the $\mathrm{BH} 4$ domain is a distinguishing feature of the anti- and pro-apoptotic family members, ${ }^{30}$ a dogma that permeates much of the current literature and many authoritative reviews. ${ }^{2} \mathrm{~A} \mathrm{BH} 4$ signature is evident enough in the sequences of $\mathrm{Bcl}-2, \mathrm{Bcl}-\mathrm{x}$ and $\mathrm{Bcl}-\mathrm{w}$, but is more controversial in $\mathrm{Mcl}-1$ and $\mathrm{A} 1$. Our structure alignments illustrate the presence of the above motif in helix $\alpha 1$ of $\mathrm{Mcl}-1$, of Bak and Bax, and of viral Bcl-2-like proteins (Figure 5). It appears that there is no basis in the $\alpha 1$ sequence for distinguishing the pro- and anti-apoptotic family members. Furthermore, binding of $\mathrm{BH} 3$ peptides to $\mathrm{Bcl}-\mathrm{x}_{\mathrm{L}}$ and $\mathrm{Mcl}-1$ does not significantly alter the environment of their $\mathrm{BH} 4$ domains. We suggest that the $\mathrm{BH} 4$ domain as defined here is a structural motif common to the Bcl-2 family fold. A functional role in antagonizing apoptosis signalling in vivo has been reported for the peptide corresponding to the $\mathrm{BH} 4$ domain of $\mathrm{Bcl}-\mathrm{x} .{ }^{31} \mathrm{An}$ inactive $\mathrm{BH} 4$ domain in that study was generated by replacing both $\phi_{1}$ and $\phi_{2}$ with glycine.

Interestingly, vaccinia virus appears to contain two functional Bcl-2 like proteins, F1L and N1L. (The sequences of these proteins are only $3 \%$ identical over the $\mathrm{Bcl}$-2-like region of F1L.) Vaccinia virus lacking N1L grows normally in culture, but it has an attenuated phenotype in mouse models. ${ }^{14} \mathrm{~N} 1 \mathrm{~L}$ reportedly binds $\mathrm{BH} 3$ peptides of $\mathrm{Bim}$, Bak and $\mathrm{Bid},{ }^{12}$ and interacts with Bad, Bax and Bid in cells transfected with the $\mathrm{N} 1 \mathrm{~L}$ gene. ${ }^{13}$ In contrast, virus lacking $\mathrm{F} 1 \mathrm{~L}(\mathrm{VV} \Delta \mathrm{F} 1 \mathrm{~L})$ results in apoptosis of infected cells in culture, ${ }^{10,15}$ suggesting that 
anti-apoptotic properties of vaccinia virus are primarily conferred by F1L. By comparison, EBV, which harbours two Bcl-2 sequence homologues BHRF-1 and BALF-1, requires both proteins to establish latent infection and to

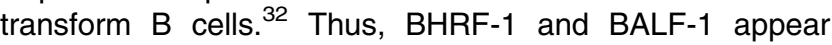
to work in concert. It remains to be seen if both $F 1 L$ and $\mathrm{N} 1 \mathrm{~L}$ are required for different stages of an infection caused by vaccinia virus.

F1L exhibits a markedly limited BH3-binding profile compared to mammalian Bcl-2 family members. Bcl- $x_{\mathrm{L}}$ has been shown to interact with numerous $\mathrm{BH}$-only proteins as well as with Bax and Bak $\mathrm{BH} 3$ domains, ${ }^{33}$ whereas $\mathrm{F} 1 \mathrm{~L}$ showed no measurable affinity for most $\mathrm{BH} 3$ peptides tested, exceptions being Bim and, to a lesser extent, Bax and Bak (Figure $3 a$ and Supplementary Figure S1). The affinity reported here for Bim is somewhat weaker than the previously reported $75 \mathrm{nM},{ }^{10}$ which may be due to the use of human Bim $\mathrm{BH} 3$ peptide in our current study compared to murine $\mathrm{Bim} \mathrm{BH} 3$ in the previous one. Furthermore, affinity measurements for wild-type $\mathrm{F} 1 \mathrm{~L}$ with wild-type $\mathrm{BH} 3$ peptides in this study were performed as direct binding experiments, thus determining dissociation constants $\left(K_{\mathrm{d}}\right)$, whereas previously ${ }^{10}$ a competition assay was employed that determined $I C_{50}$ values. Although only very weak binding was detected here to the $\mathrm{BH} 3$ peptide from Bak, interaction between $\mathrm{F} 1 \mathrm{~L}$ and Bak in transfected cells has been observed. ${ }^{15}$ This might suggest a synergy deriving from the co-localization of Bak and F1L on the mitochondrial membrane, or the importance of regions of Bak and $\mathrm{F} 1 \mathrm{~L}$ other than the tongue-in-groove components (for example, the membrane anchoring regions), in the interaction. In contrast, we have measured a weak interaction with the $\mathrm{Bax} \mathrm{BH} 3$, but no association of $\mathrm{F} 1 \mathrm{~L}$ with Bax in a cell has been reported, other than following detergent activation of Bax. ${ }^{16}$ Instead, experimental evidence supports a role for $\mathrm{F} 1 \mathrm{~L}$ in blocking activation of Bax in the absence of direct binding to it. ${ }^{16}$ It is possible that the weak interaction we describe here between the $\mathrm{Bax} \mathrm{BH} 3$ and $\mathrm{F} 1 \mathrm{~L}$ has little or no role in controlling Bax activation. The tighter interaction we describe between Bim BH3 and F1L might explain F1L's antagonism of $\mathrm{Bax}$ activation through a sequestration mechanism to prevent Bim binding either directly to Bax or indirectly to Bcl-2 family members. ${ }^{16}$ Vaccinia virus-induced apoptosis is reduced in Bim-deficient cells, ${ }^{16}$ suggesting that $\mathrm{Bim}$, and potentially other $\mathrm{BH}$-only proteins, is upregulated or activated in response to infection by vaccinia virus.

The affinities measured for Bim and $\mathrm{Bax} \mathrm{BH} 3$ domains are modest compared to the low nanomolar affinities reported for most mammalian Bcl-2 members. ${ }^{33}$ Nevertheless, VV $\Delta \mathrm{F} 1 \mathrm{~L}$ triggers apoptosis, suggesting that $\mathrm{F} 1 \mathrm{~L}$ is indeed the predominant anti-apoptotic protein expressed by vaccinia virus, despite the low affinity for $\mathrm{BH} 3$ ligands. It will be interesting to determine whether or not the dimeric form of $\mathrm{F} 1 \mathrm{~L}$ contributes to its potent ability to inhibit apoptosis.

The apoptotic machinery has emerged as a promising drug target for cancer therapy following the discovery of organic molecules that can mimic the pro-apoptotic function of certain $\mathrm{BH} 3$ domain-containing proteins. ${ }^{34,35}$ Similarly, the putative $\mathrm{BH}$-binding groove of $\mathrm{F} 1 \mathrm{~L}$ described here may be a valid target for therapies whose mode of action would be to trigger apoptosis in vaccinia virus-infected cells. Although variola virus is essentially eradicated in the community, concerns persist about its re-emergence as a potential bioweapon. ${ }^{36}$

\section{Materials and Methods}

Recombinant protein production. The complete CDNA of F1L MVA was used to amplify by polymerase chain reaction (PCR) the region coding for residues 18-186 of F1L. The forward primers introduced a BamHI restriction site, and the reverse primer introduced a stop codon followed by an EcoRI site. The PCR product was cloned into the pET DUET vector (Invitrogen) or pGEX-6P3 vector (GE Healthcare) using BamHI and EcoRI, and expressed in Escherichia coli BL21 (DE3) pLysS cells. Cells were grown from an overnight culture to an $\mathrm{OD}_{600}$ of 1.0-1.2. Protein expression was induced with $500 \mathrm{mM}$ isopropyl- $\beta$-D-thiogalactopyranoside for $4 \mathrm{~h}$, after which the cells were pelleted by centrifugation. For protein purification, cell pellets were homogenized using an Avestin EmulsiFlex homogenizer in lysis buffer (20 mM Tris- $\mathrm{HCl}$ pH 8.0, $150 \mathrm{mM} \mathrm{NaCl}, 10 \mathrm{mM}$ 2-mercaptoethanol). Cell lysates containing hexahistidine-tagged $\mathrm{F} 1 \mathrm{~L}$ were centrifuged and filtered before loading onto a $1 \mathrm{ml} \mathrm{Hi-Trap} \mathrm{chelating} \mathrm{column} \mathrm{(GE} \mathrm{Healthcare)} \mathrm{charged} \mathrm{with} \mathrm{nickel.}$ The protein was eluted in $50 \mathrm{mM}$ Tris $\mathrm{pH} 8.0,150 \mathrm{mM} \mathrm{NaCl}, 10 \mathrm{mM}$ 2-mercaptoethanol and $250 \mathrm{mM}$ imidazole and subjected to preparative gel-filtration chromatography in $20 \mathrm{mM}$ Hepes $\mathrm{pH} 7.5,150 \mathrm{mM} \mathrm{NaCl}$ and $10 \mathrm{mM}$ DTT using a Superdex 200 column, where it eluted as a single peak. Cell lysates containing GST-tagged F1L were centrifuged and filtered before loading onto a glutathione Sepharose column (GE Healthcare) and washed with buffer. F1L was eluted with Tris $\mathrm{pH}$ 8.0, $150 \mathrm{mM} \mathrm{NaCl}, 10 \mathrm{mM} \mathrm{DTT}$ and $10 \mathrm{mM}$ glutathione, and further purified on a Superdex 200 column in $20 \mathrm{mM}$ Hepes pH 7.5, $150 \mathrm{mM} \mathrm{NaCl}$ and $10 \mathrm{mM}$ DTT.

Crystallization and structure determination. Crystals of $\mathrm{F} 1 \mathrm{~L}$ were grown by the sitting drop method at room temperature in $0.9-1.2 \mathrm{M} \mathrm{NaCl}$ and $50 \mathrm{mM}$ $\mathrm{Na} / \mathrm{K}$ phosphate $\mathrm{pH}$ 5.2. The crystals belong to space group P23 with $a=88.26 \AA$. The asymmetric unit contains one protein chain and $54 \%$ solvent. Diffraction data were collected from frozen crystals at $100 \mathrm{~K}$ using a Raxis $4++$ image plate detector mounted on a Rigaku Micromax 007 rotating anode X-ray generator equipped with an AXCO capillary optics (CuK $\alpha$ radiation $\lambda=1.54 \AA$ ). Diffraction data were processed with HKL2000. A heavy atom derivative was obtained by soaking crystals in mother liquor supplemented with $1 \mathrm{M} \mathrm{Nal}$ for $30 \mathrm{~s}$. Heavy atom sites were found and refined with SHELX. After density modification, a final model was built with $\operatorname{Coot}^{37}$ and refined with Refmac5. Crystallographic data are summarized in Table 2. The coordinates have been deposited in the Protein Data Bank (accession code 2vty). Figures were prepared using PyMol.

Measurement of dissociation constants. Biacore competition assays were performed as described. ${ }^{33}$.Direct binding assays were performed on a Biacore $\mathrm{S} 51$. Affinity measurements were performed at room temperature on a Biacore S51 biosensor with $0.15 \mathrm{M} \mathrm{NaCl}, 3 \mathrm{mM}$ EDTA, $0.005 \%$ Surfactant P20, 5\% (v/v) DMSO and $0.01 \mathrm{M} \mathrm{Hepes} \mathrm{pH} 7.4$ as the running buffer. Anti-GST antibodies (Qiagen) were immobilized on CM5 sensorchips using amine-coupling chemistry. Recombinant F1L $(100 \mu \mathrm{g} / \mathrm{ml})$ was then injected at the flow rate of $10 \mu / / \mathrm{min}$ and captured via an $\mathrm{N}$-terminal GST. All BH3 domain peptides (Mimotopes) were prepared in running buffer. Several concentrations of peptide around that peptide's $K_{d}$ were injected at a flow rate of $90 \mu / \mathrm{min}$. Peptides were allowed to associate with the protein for $60 \mathrm{~s}$ and dissociation was monitored for $60 \mathrm{~s}$. All sensorgrams were generated using double referencing by subtracting the binding response from a reference spot, followed by corrections for solvent bulk shifts and subtraction of an average of the running buffer only injections over the immobilized spot. For $K_{\mathrm{d}}$ calculation, corrected response data were fitted using a 1:1 binding site model including mass transport limitations.

Analytical ultracentrifugation. Sedimentation velocity experiments were conducted in a Beckman model XL-I analytical ultracentrifuge at a temperature of $20^{\circ} \mathrm{C}$. A $380 \mu \mathrm{l}$ volume of sample $(1.0 \mathrm{mg} / \mathrm{ml})$ and $400 \mu \mathrm{l}$ of reference solution (25 mM KH $\left.2 \mathrm{PO}_{4}, 150 \mathrm{mM} \mathrm{NaCl}, \mathrm{pH} 7.5\right)$ were loaded into a conventional double sector quartz cell and mounted in a Beckman 4-hole An-60 Ti rotor. Samples were centrifuged at a rotor speed of 40000 r.p.m. and the data were collected at a single wavelength ( $275 \mathrm{~nm}$ for $\mathrm{F} 1 \mathrm{~L}$ and $293 \mathrm{~nm}$ for $\mathrm{Bcl}-\mathrm{x}_{\mathrm{L}}$ ) in continuous mode, using a time interval of $300 \mathrm{~s}$ and a step size of $0.003 \mathrm{~cm}$ without averaging. Solvent density $\left(1.007 \mathrm{~g} / \mathrm{ml}\right.$ at $\left.20^{\circ} \mathrm{C}\right)$ and viscosity $(1.021 \mathrm{cP})$, as well as estimates of the partial specific volume $\left(0.723 \mathrm{ml} / \mathrm{g}\right.$ for $\mathrm{F} 1 \mathrm{~L}$ and $0.726 \mathrm{ml} / \mathrm{g}$ for $\mathrm{Bcl}-\mathrm{x}_{\mathrm{L}}$ at $\left.20^{\circ} \mathrm{C}\right)$ and hydration 
Table 2 Crystallographic statistics

\begin{tabular}{|c|c|c|c|}
\hline Crystal & $\begin{array}{c}\text { F1L } \\
\text { native }\end{array}$ & $\begin{array}{l}\text { F1L } \\
\text { Nal }\end{array}$ & $\begin{array}{l}\text { F1L } \\
\text { high }\end{array}$ \\
\hline $\begin{array}{l}\text { Data collection and phasin } \\
\text { Space group } \\
\text { Resolution range }(\AA) \\
\text { Unique reflections } \\
\text { Multiplicity } \\
{\text { Completeness }(\%)^{\mathrm{a}}}^{R_{\text {merg }}} \\
R_{\text {deriv }} \\
R_{\text {cullis }} \text { (centric/acentric) } \\
\text { Phasing power (centric/ } \\
\text { acentric) }\end{array}$ & $\begin{array}{c}\text { P23 } \\
50-2.9 \\
5299 \\
4.9(4.2) \\
99.8(100) \\
0.167(0.479) \\
\end{array}$ & $\begin{array}{c}\text { P23 } \\
50-3.2 \\
3957 \\
7.5(7.4) \\
99.8 \\
0.227 \\
0.212 \\
0.653 / 0.609 \\
1.46 / 1.39\end{array}$ & $\begin{array}{c}\text { P23 } \\
50-2.1 \\
13687 \\
5.1(5.1) \\
99.4(99.9) \\
0.090(0.548) \\
\end{array}$ \\
\hline $\begin{array}{l}\text { Refinement } \\
\text { Resolution range }(\AA) \\
\text { Reflections (working set/ } \\
\text { test set) } \\
\text { Protein atoms } \\
\text { Solvent atoms } \\
R_{\text {cryst }} / R_{\text {free }} \\
\text { r.m.s.d. bonds }(\AA) \\
\text { r.m.s.d. angles (deg) } \\
\text { Ramachandran plot }(\%)^{g}\end{array}$ & & & $\begin{array}{c}50-2.1 \\
12940 / 680 \\
\\
2065 \\
68 \mathrm{H}_{2} \mathrm{O} \\
0.192 / 0.207 \\
0.017 \\
1.6 \\
97.0 / 3.0 / 0.0 / 0 .\end{array}$ \\
\hline
\end{tabular}

${ }^{a}$ Numbers in parentheses refer to the highest resolution shells. ${ }^{\mathrm{b}} R_{\text {merge }}=\sum_{h} \sum_{i} l_{i}(h)-\langle I(h)\rangle \mid / \sum_{h} \sum_{i} l_{i}(h)$, where $I_{i}(h)$ is the th measurement of reflection $h$ and $\langle I(h)\rangle$ is the weighted mean of all measurements of $h$. ${ }^{\mathrm{c}} R_{\text {deriv }}=\sum_{h} \| F_{\mathrm{PH}}|-| F_{\mathrm{P}}|| / \sum_{h}\left|F_{\mathrm{P}}\right|$, where $F_{\mathrm{P}}$ and $F_{\mathrm{PH}}$ are the native and derivative structure factors, respectively. ${ }^{\mathrm{d}} R_{\mathrm{cullis}}=\sum h||\left|F_{\mathrm{PH}}\right|-\left|F_{\mathrm{P}} \|-\right| F_{\mathrm{H}}|| / \sum_{h}|| F_{\mathrm{PH}}|-| F_{\mathrm{P}} \mid$, where $F_{H}$ is the calculated heavy atom structure factor. ${ }^{e}$ Phasing power is defined as (r.m.s. $F_{\mathrm{H}} /$ r.m.s. lack of closure). ${ }^{\mathrm{t}} R=\sum_{h} \mid F_{\text {obs }}-F_{\text {calc }} / / \sum_{h} F_{\text {obs }}$, where $F_{\text {obs }}$ and $F_{\text {calc }}$ are the observed and calculated structure factor amplitudes, respectively. $R_{\text {cryst }}$ and $R_{\text {free }}$ were calculated using the working and test set, respectively. ${ }^{9}$ Residues in most favoured, additionally allowed, generously allowed and disallowed regions.

estimate $\left(0.401 \mathrm{~g} / \mathrm{g}\right.$ for $\mathrm{F} 1 \mathrm{~L}$ and $0.381 \mathrm{~g} / \mathrm{g}$ for $\left.\mathrm{Bcl}-\mathrm{x}_{\mathrm{L}}\right)$ were computed using the program SEDNTERP. ${ }^{38}$ Sedimentation velocity data at multiple time points were fitted to either a non-interacting discrete species model of up to three components or a continuous size-distribution model using the program SEDFIT, which is available at www.analyticalultracentrifugation.com.

Acknowledgements. We thank G Häcker for the F1L cDNA; J Szarlat for computational and $\mathrm{J}$ Blyth and $\mathrm{A}$ Wardak for technical assistance; staff at the beamline ID23.1 at ESRF Grenoble for help with X-ray data collection; C3 Collaborative Crystallization Centre for assistance with crystallization; C Day, $G$ Dewson, J Gulbis, G Häcker, M Hinds, E Lee, B Smith and I Street for discussions; and $M$ Hinds for reagents. Our work is supported by scholarships, fellowships and grants from Cancer Council of Victoria (to PMC and WDF), NHMRC (Program Grant 257502; fellowships to DCSH, PMC and WDF), US NCl (CA80188 and CA43540), ARC (ADP0556836, LE0560722 and AB07CBT004 to MAP) and the Leukemia \& Lymphoma Society (SCOR 7015-02; fellowship to MK).

Coordinates for F1L were deposited with the Protein Data Bank, accession code 2vty.

1. Cuconati A, White E. Viral homologs of BCL-2: role of apoptosis in the regulation of virus infection. Genes Dev 2002; 16: 2465-2478.

2. Adams JM, Cory S. The Bcl-2 apoptotic switch in cancer development and therapy. Oncogene 2007; 26: 1324-1337.

3. Youle RJ, Strasser A. The BCL-2 protein family: opposing activities that mediate cell death. Nat Rev Cell Biol 2008; 9: 47-59.

4. Sattler M, Liang H, Nettesheim D, Meadows RP, Harlan JE, Eberstadt M et al. Structure of Bcl- $x_{L}-B a k$ peptide complex: recognition between regulators of apoptosis. Science 1997; 275: 983-986.
5. Liu X, Dai S, Zhu Y, Marrack P, Kappler JW. The structure of a $\mathrm{Bcl}-\mathrm{X}_{\llcorner} / \mathrm{Bim}$ fragment complex: implications for Bim function. Immunity 2003; 19: 341-352.

6. Lindsten T, Ross AJ, King A, Zong W, Rathmell JC, Shiels HA et al. The combined functions of proapoptotic Bcl-2 family members Bak and Bax are essential for normal development of multiple tissues. Mol Cell 2000; 6: 1389-1399.

7. Graham KA, Opgenorth A, Upton C, McFadden G. Myxoma virus M11L ORF encodes a protein for which cell surface localization is critical in manifestation of viral virulence. Virology 1992; 191: 112-124.

8. Goldmacher VS, Bartle LM, Skaletskaya A, Dionne CA, Kedersha NL, Vater CA et al. A cytomegalovirus-encoded mitochondria-localized inhibitor of apoptosis structurally unrelated to bcl-2. Proc Natl Acad Sci USA 1999; 96: 12536-12541.

9. Wasilenko ST, Stewart TL, Meyers AF, Barry M. Vaccinia virus encodes a previously uncharacterized mitochondrial-associated inhibitor of apoptosis. Proc Natl Acad Sci USA 2003; 100: 14345-14350.

10. Fischer SF, Ludwig H, Holzapfel J, Kvansakul M, Chen L, Huang DCS et al. Modified vaccinia virus ankara protein $\mathrm{F} 1 \mathrm{~L}$ is a novel $\mathrm{BH}$-domain binding protein and acts together with the early viral protein E3L to block virus-associated apoptosis. Cell Death Differ 2006; 13: $109-118$.

11. Kvansakul M, van Delft MF, Lee EF, Gulbis JM, Fairlie WD, Huang DC et al. A structural viral mimic of prosurvival bcl-2: a pivotal role for sequestering proapoptotic bax and bak. Mol Cell 2007; 25: 933-942.

12. Aoyagi M, Zhai D, Jin C, Aleshin AE, Stec B, Reed JC et al. Vaccinia virus N1L protein resembles a B cell lymphoma-2 (Bcl-2) family protein. Protein Sci 2007; 16: 118-124.

13. Cooray S, Bahar MW, Abrescia NG, McVey CE, Bartlett NW, Chen RA et al. Functional and structural studies of the vaccinia virus virulence factor $\mathrm{N} 1$ reveal a Bcl-2-like anti-apoptotic protein. J Gen Virol 2007; 88 (Part 6): 1656-1666.

14. Bartlett N, Symons JA, Tscharke DC, Smith GL. The vaccinia virus N1L protein is an intracellular homodimer that promotes virulence. J Gen Virol 2002; 83 (Part 8): 1965-1976.

15. Wasilenko ST, Banadyga L, Bond D, Barry M. The vaccinia virus $F 1 L$ protein interacts with the proapoptotic protein Bak and inhibits Bak activation. J Virol 2005; 79: 14031-14043.

16. Taylor JM, Quilty D, Banadyga L, Barry M. The vaccinia virus protein F1L interacts with Bim and inhibits activation of the pro-apoptotic protein Bax. J Biol Chem 2006; 281 39728-39739.

17. Postigo A, Cross JR, Downward J, Way M. Interaction of F1L with the BH3 domain of Bak is responsible for inhibiting vaccinia-induced apoptosis. Cell Death Differ 2006; 13: 1651-1662.

18. Bennett MJ, Schlunegger MP, Eisenberg D. 3D domain swapping: a mechanism for oligomer assembly. Protein Sci 1995; 4: 2455-2468.

19. Muchmore SW, Sattler M, Liang H, Meadows RP, Harlan JE, Yoon HS et al. X-ray and NMR structure of human Bcl- $x_{L}$, an inhibitor of programmed cell death. Nature 1996; 381 335-341.

20. Czabotar PE, Lee EF, van Delft MF, Day CL, Smith BJ, Huang DC et al. Structural insights into the degradation of Mcl-1 induced by BH3 domains. Proc Natl Acad Sci USA 2007; 104: 6217-6222.

21. Oberstein A, Jeffrey PD, Shi Y. Crystal structure of the BCl-XL-Beclin 1 peptide complex: Beclin 1 is a novel BH3-only protein. J Biol Chem 2007; 282: 13123-13132.

22. O'Neill JW, Manion MK, Maguire B, Hockenbery DM. BCL-XL dimerization by threedimensional domain swapping. J Mol Biol 2006; 356: 367-381.

23. Hsu YT, Youle RJ. Nonionic detergents induce dimerization among members of the $\mathrm{Bcl}-2$ family. J Biol Chem 1997; 272: 13829-13834.

24. Cartron PF, Gallenne T, Bougras G, Gautier F, Manero F, Vusio P et al. The first alpha helix of Bax plays a necessary role in its ligand-induced activation by the BH3-only proteins Bid and PUMA. Mol Cell 2004; 16: 807-818.

25. Hinds MG, Smits C, Fredericks-Short R, Risk JM, Bailey M, Huang DC et al. Bim, Bad and Bmf: intrinsically unstructured BH3-only proteins that undergo a localized conformational change upon binding to prosurvival Bcl-2 targets. Cell Death Differ 2007; 14: 128-136.

26. O'Connor L, Strasser A, O'Reilly LA, Hausmann G, Adams JM, Cory $S$ et al. Bim: a novel member of the Bcl-2 family that promotes apoptosis. EMBO J 1998; 17: 384-395.

27. Moldoveanu T, Liu Q, Tocilj A, Watson M, Shore G, Gehring K. The X-ray structure of a BAK homodimer reveals an inhibitory zinc binding site. Mol Cell 2006; 24: $677-688$.

28. Willis SN, Chen L, Dewson G, Wei A, Naik E, Fletcher $\mathrm{Jl}$ et al. Pro-apoptotic Bak is sequestered by Mc1-1 and Bcl-xL, but not Bcl-2, until displaced by BH3-only proteins. Genes Dev 2005; 19: 1294-1305.

29. Stewart TL, Wasilenko ST, Barry M. Vaccinia virus F1L protein is a tail-anchored protein that functions at the mitochondria to inhibit apoptosis. J Virol 2005; 79: 1084-1098.

30. Zha H, Aime-Sempe C, Sato T, Reed JC. Proapoptotic protein Bax heterodimerizes with $\mathrm{BCl}-2$ and homodimerizes with Bax via a novel domain (BH3) distinct from $\mathrm{BH} 1$ and $\mathrm{BH} 2$. J Biol Chem 1996; 271: 7440-7444.

31. Sugioka R, Shimizu S, Funatsu T, Tamagawa H, Sawa Y, Kawakami T et al. BH4-domain peptide from Bcl-XL exerts anti-apoptotic activity in vivo. Oncogene 2003; 22: 8432-8440.

32. Altmann M, Hammerschmidt W. Epstein-Barr virus provides a new paradigm: a requirement for the immediate inhibition of apoptosis. PLOS Biol 2005; 3: e404.

33. Chen L, Willis SN, Wei A, Smith BJ, Fletcher JI, Hinds MG et al. Differential targeting of prosurvival $\mathrm{BCl}-2$ proteins by their $\mathrm{BH} 3$-only ligands allows complementary apoptotic function. Mol Cell 2005; 17: 393-403. 
34. Oltersdorf T, Elmore SW, Shoemaker AR, Armstrong RC, Augeri DJ, Belli BA et al. An inhibitor of Bcl-2 family proteins induces regression of solid tumours. Nature 2005; 435 : $677-681$.

35. Lee EF, Czabotar PE, Smith BJ, Deshayes K, Zobel K, Colman PM et al. Crystal structure of ABT-737 complexed with Bcl-xL: implications for selectivity of antagonists of the Bcl-2 family. Cell Death Differ 2007; 14: 1711-1713.

36. Kaiser J. Smallpox vaccine. A tame virus runs amok. Science 2007; 316: 1418-1419.

37. Emsley P, Cowtan K. Coot: model-building tools for molecular graphics. Acta Crystallogr 2004; 60 (Part 12): 2126-2132.
38. Laue TM, Shah BD, Ridgeway TM, Pelletier SL. Computer-aided interpretation of analytical sedimentation data for proteins In: Harding SE et al. (eds). Analytical Ultracentrifugation in Biochemistry and Polymer Science. The Royal Society of Chemistry: Cambridge, 1992, pp $90-125$.

39. Hinds MG, Lackmann M, Skea GL, Harrison PJ, Huang DC, Day CL. The structure of Bcl-w reveals a role for the $\mathrm{C}$-terminal residues in modulating biological activity. EMBO J 2003; 22: 1497-1507.

40. Berman HM, Westbrook J, Feng Z, Gilliland G, Bhat TN, Weissig $\mathrm{H}$ et al. The protein data bank. Nucleic Acids Res 2000; 28: 235-242.

Supplementary Information accompanies the paper on Cell Death and Differentiation website (http://www.nature.com/cdd) 